\title{
PARTIAL DIFFERENTIATION OF AIR DENSITY IN MASS METROLOGY
}

\author{
M. L. Win ${ }^{1}$, T. Sanponpute ${ }^{2}$, B. Suktat ${ }^{3}$ \\ ${ }^{1}$ National Institute of Metrology (Myanmar), Yangon, Myanmar, marlarwin99@gmail.com \\ ${ }^{2}$ National Institute of Metrology (Thailand), Pathumthani, Thailand, tassanai@nimt.or.th \\ ${ }^{3}$ Consultant, Pathumthani, Thailand, bunjobs@hotmail.com
}

\begin{abstract}
:
There are four major uncertainty components to be considered when performing mass comparisons. They are uncertainties of weighing process, reference weight used, air buoyancy, and mass comparator. The systematic effect of air buoyancy can be greatly reduced if the air density and the densities of the test and reference weights are known. This paper will emphasis on the uncertainty due to air buoyancy correction only. To calculate the uncertainty of air density correction, partial derivatives of temperature, barometric pressure and humidity must be performed. In this paper, two methods for partial differentiation of air density components are discussed.
\end{abstract}

Keywords: air buoyancy; air density; partial differentiation of air density; August-RocheMagnus approximation equation

\section{INTRODUCTION}

In Mass Metrology, there are many important influence quantities have to be taken into account. These include thermal stabilisation time, magnetic susceptibility, density of standard and test weights, environmental conditions, weighing instrument, weighing cycles etc. According to OIML R111-1[1, equation C.6.5-1], the combined standard uncertainty for mass comparison process is calculated using equation (1).

$$
u_{\mathrm{c}}\left(m_{\mathrm{ct}}\right)=\sqrt{u_{\mathrm{w}}^{2}\left(\overline{\Delta m_{\mathrm{c}}}\right)+u^{2}\left(m_{\mathrm{cr}}\right)+u_{\mathrm{b}}^{2}+u_{\mathrm{ba}}^{2}}
$$

where:

$u_{\mathrm{c}}\left(m_{\mathrm{ct}}\right)=$ combined standard uncertainty of the conventional mass of the test weight

$u_{\mathrm{w}}\left(\overline{\Delta m_{\mathrm{c}}}\right)=$ uncertainty of the weighing process

$u\left(m_{\mathrm{cr}}\right) \quad=$ uncertainty of the reference weight

$u_{\mathrm{b}} \quad=$ uncertainty of the air buoyancy correction

$u_{\mathrm{ba}} \quad=$ uncertainty of the balance

\section{THE SYSTEMATIC EFFECTS OF AIR DENSITY}

When highly accurate mass comparisons are performed under the laboratory conditions, buoyant force that acts upon weights, depending on their volume and the air density, can cause significant systematic error to the measurement results. The systematic effects of air buoyancy can be corrected if the air density is known. The air density is a function of various influence quantities such as temperature, barometric pressure and humidity. To correct for the effect of air density, OIML R111-1 provides the following equation [1, Eq. 10.2-1]:

$m_{\mathrm{ct}}=m_{\mathrm{cr}}(1+C)+\Delta \overline{m_{\mathrm{c}}}$

with [1, Eq. 10.2-2]:

$$
C=\left(\rho_{\mathrm{a}}-\rho_{0}\right)\left[\frac{\rho_{\mathrm{t}}-\rho_{\mathrm{r}}}{\rho_{\mathrm{r}} \rho_{\mathrm{t}}}\right]
$$

where:

$m_{\mathrm{ct}}=$ conventional mass of the test weight

$m_{\mathrm{cr}}=$ conventional mass of the reference weight

$\Delta \overline{m_{\mathrm{c}}}=$ average weighing difference observed between test and reference weight

$C=$ correction factor for air buoyancy

$\rho_{\mathrm{a}} \quad=$ density of moist air

$\rho_{0} \quad=$ density of air as a reference value equal to $1.2 \mathrm{~kg} \cdot \mathrm{m}^{-3}$

$\rho_{\mathrm{t}} \quad=$ density of the test weight

$\rho_{\mathrm{r}} \quad=$ density of the reference weight

The uncertainty of air buoyancy correction is calculated according to OIML R111-1, as follows [1, equation C.6.3-1]:

$$
\begin{aligned}
u_{\mathrm{b}}^{2} & =\left[m_{\mathrm{cr}} \frac{\rho_{\mathrm{r}}-\rho_{\mathrm{t}}}{\rho_{\mathrm{r}} \rho_{\mathrm{t}}} u\left(\rho_{\mathrm{a}}\right)\right]^{2}+\left[m_{\mathrm{cr}}\left(\rho_{\mathrm{a}}-\rho_{0}\right)\right]^{2} \frac{u^{2}\left(\rho_{\mathrm{t}}\right)}{\rho_{\mathrm{t}}^{4}} \\
& +m_{\mathrm{cr}}^{2}\left(\rho_{\mathrm{a}}-\rho_{0}\right)\left[\left(\rho_{\mathrm{a}}-\rho_{0}\right)-2\left(\rho_{\mathrm{al}}-\rho_{0}\right)\right] \frac{u^{2}\left(\rho_{\mathrm{r}}\right)}{\rho_{\mathrm{r}}^{4}}
\end{aligned}
$$

where:

$u_{\mathrm{b}} \quad=$ uncertainty of the air buoyancy correction

$m_{\mathrm{cr}}=$ conventional mass of the reference weight

$\rho_{\mathrm{r}} \quad=$ density of the reference weight 
$\rho_{\mathrm{t}} \quad=$ density of the test weight

$u\left(\rho_{\mathrm{a}}\right)=$ uncertainty of density of moist air

$\rho_{\mathrm{a}} \quad=$ density of moist air

$\rho_{0} \quad=$ density of the air as a reference value equal to $1.2 \mathrm{~kg} \cdot \mathrm{m}^{-3}$

$u\left(\rho_{\mathrm{t}}\right)=$ uncertainty of density of the test weight

$\rho_{\mathrm{al}} \quad=$ air density during the (previous) calibration of the reference weight $u\left(\rho_{\mathrm{r}}\right)=$ uncertainty of density of reference weight

\section{UNCERTAINTY OF AIR DENSITY}

For air density $\rho_{\mathrm{a}}$, OIML R111 provides an approximation formula [1, equation E.3-1] given as equation (5).

$\rho_{\mathrm{a}}=\frac{0.34848 p-0.009 \mathrm{hr} \times \exp (0.061 \mathrm{t})}{273.15+t}$

where:

$\rho_{\mathrm{a}}=$ air density, in $\mathrm{kg} \cdot \mathrm{m}^{-3}$

$p=$ air pressure, in mbar or $\mathrm{hPa}$

$h r=$ relative humidity, in $\%$

$t=$ air temperature, in ${ }^{\circ} \mathrm{C}$

Equation (5) has a relative uncertainty of $2 \times 10^{-4}$ in the ranges $900 \mathrm{hPa}<p<1100 \mathrm{hPa}$, $10{ }^{\circ} \mathrm{C}<t<30{ }^{\circ} \mathrm{C}$ and $\mathrm{hr}<80 \%$. Under reference conditions of $p=1013.25 \mathrm{hPa}, t=20^{\circ} \mathrm{C}$, and $h r=50 \%$, equation (5) gives an air density of $1.199294 \mathrm{~kg} \cdot \mathrm{m}^{-3}$.

The variance of air density is obtained from equation (6) [1, equation C.6.3-3].

$$
\begin{aligned}
u^{2}\left(\rho_{\mathrm{a}}\right)=u_{\mathrm{F}}^{2}+ & {\left[\frac{\partial \rho_{\mathrm{a}}}{\partial p} u_{p}\right]^{2}+\left[\frac{\partial \rho_{\mathrm{a}}}{\partial t} u_{t}\right]^{2} } \\
& +\left[\frac{\partial \rho_{\mathrm{a}}}{\partial h r} u_{h r}\right]^{2}
\end{aligned}
$$

Under the same reference conditions, the following numerical values for sensitivity coefficients are given:

- $u_{\mathrm{F}}=$ [uncertainty of the formula used] (for CIPM formula $u_{\mathrm{F}}=10^{-4} \rho_{\mathrm{a}}$ )

- $\frac{\partial \rho_{\mathrm{a}}}{\partial p}=10^{-5} \rho_{\mathrm{a}} \mathrm{Pa}^{-1}$

- $\frac{\partial \rho_{\mathrm{a}}}{\partial t}=-3.4 \times 10^{-3} \rho_{\mathrm{a}} \mathrm{K}^{-1}$

- $\frac{\partial \rho_{\mathrm{a}}}{\partial h r}=-10^{-2} \rho_{\mathrm{a}}$

However, if we calculate the three sensitivity coefficients by partial differentiation of equation (5), we obtain:

$$
\begin{aligned}
\frac{\partial \rho_{\mathrm{a}}}{\partial p}= & \frac{0.34848}{273.15+t} \rho_{\mathrm{a}} \\
& =\frac{0.34848}{293.15} \rho_{\mathrm{a}}=10^{-5} \rho_{\mathrm{a}} \mathrm{Pa}^{-1}
\end{aligned}
$$

$$
\begin{aligned}
& \frac{\partial \rho_{\mathrm{a}}}{\partial h r}=\frac{-0.009 \times \exp (0.061 t)}{273.15+t} \rho_{\mathrm{a}} \\
& \quad=\frac{-0.009 \times \exp (0.061 \times 20)}{273.15+20} \rho_{\mathrm{a}}=-10^{-2} \rho_{\mathrm{a}}
\end{aligned}
$$

$\frac{\partial \rho_{\mathrm{a}}}{\partial t}=\frac{-0.34848 p}{(273.15+t)^{2}}-$

$$
\frac{0.009 h r\left[(273.15+t) \frac{d e^{0.061 t}}{d t}-e^{0.061 t} \frac{d^{(273.15+t)}}{d t}\right]}{(273.15+t)^{2}} \rho_{\mathrm{a}}
$$$$
=\frac{-0.34848 p}{(273.15+t)^{2}}-
$$

$$
\frac{0.009(50) e^{0.061 t}[293.15 \times 0.061-1]}{(273.15+t)^{2}} \rho_{\mathrm{a}}
$$

$$
\begin{aligned}
= & \frac{-0.34848 \times 1013.15}{(273.15+20)^{2}}- \\
& \frac{0.009(50) e^{0.061 \times 20}[293.15 \times 0.061-1]}{(273.15+20)^{2}} \rho_{\mathrm{a}}
\end{aligned}
$$

$=-4.4 \times 10^{-3} \rho_{\mathrm{a}} \mathrm{K}^{-1}$

From the above calculations, we found that sensitivity coefficient $\frac{\partial \rho_{\mathrm{a}}}{\partial p}$ and $\frac{\partial \rho_{\mathrm{a}}}{\partial h r}$ values are exactly the same as OIML R111 values, but not the value of $\frac{\partial \rho_{\mathrm{a}}}{\partial t}$. Therefore, we try to consider how to obtain the same $\frac{\partial \rho_{\mathrm{a}}}{\partial t}$ value as provided by OIML R111.

According to the August-Roche-Magnus approximation equation [4, equation 4],

$$
R H=100 \times \frac{e \frac{17.625 T D}{243.04+T D}}{e \frac{17.625 t}{243.04+t}}
$$

The changes in temperature $t$ will also cause the relative humidity $R H$ to change, if the dew point temperature $T D$ is kept constant. In this case, we need to consider not only the changes in temperature but also the correlation between temperature and relative humidity according to August-RocheMagnus approximation equation. In this equation, there are three variables, namely temperature $t$, relative humidity $R H$ and dew point temperature $T D$.

The dew point temperature can be calculated by using August-Roche-Magnus approximation equation [4, equation 5] as follows:

$$
T D=243.04 \frac{\ln \left(\frac{R H}{100}\right)+\left(\frac{17.625 t}{243.04+t}\right)}{\left(17.625-\ln \left(\frac{R H}{100}\right)-\frac{17.625 t}{(243.04+t)}\right)}
$$


Substituting in values of $R H=50 \%, t=20^{\circ} \mathrm{C}$ and $p=101325 \mathrm{~Pa}$, we get:

$T D=9.261^{\circ} \mathrm{C}$

If we keep TD constant at $9.261{ }^{\circ} \mathrm{C}$ while the temperature changes from; $t=20^{\circ} \mathrm{C}$ to $t=21{ }^{\circ} \mathrm{C}$, from equation (11), we get:

For $t=20^{\circ} \mathrm{C}$ :

$$
R H=100 \times \frac{e \frac{17.625 \times 9.261}{243.04+9.261}}{e \frac{17.625 \times 20}{243.04+20}}=50 \%
$$

For $t=21^{\circ} \mathrm{C}$ :

$$
R H=100 \times \frac{e \frac{17.625 \times 9.261}{243.04+9.261}}{e \frac{17.625 \times 21}{243.04+21}}=47 \%
$$

From the above examples, the change of temperature from $20^{\circ} \mathrm{C}$ to $21^{\circ} \mathrm{C}$ can cause the relative humidity to change from $50 \% \mathrm{RH}$ to $47 \% \mathrm{RH}$. Thus the air density also changes to:

$$
\begin{gathered}
\rho_{\mathrm{a} 1}=\frac{0.34848 \times 1013.25-0.009(47) \mathrm{e}^{0.061 \times 21}}{273.15+21} \\
=1.195221 \mathrm{~kg} \cdot \mathrm{m}^{-3}
\end{gathered}
$$

And thus, from equations (5) and (15):

$$
\begin{gathered}
\frac{\partial \rho_{a}}{\partial t}=\frac{\rho_{a 1}-\rho_{0}}{\rho_{0}}=\frac{1.195221-1.199294}{1.199294} \\
=-3.4 \times 10^{-3} \rho_{a} \mathrm{~K}^{-1}
\end{gathered}
$$

This value of $\frac{\partial \rho_{a}}{\partial t}$ is now exactly the same as the value provided in OIML R111. Therefore, we need to consider the correlation between temperature and humidity when we perform partial differentiation of temperature against the air density.

Note: In the August-Roche-Magnus approximation equation, there are three variables, namely temperature $t$, relative humidity $R H$ and dew point temperature $T D$. For our purposes, dew point temperature $T D$ is considered constant while the temperature $t$ is changing. In this case any changes in temperature will also cause the relative humidity to change in the opposite direction. Otherwise, we would not get the same value of $\frac{\partial \rho_{a}}{\partial t}$ as that provided in OIML R111.

\section{DISCUSSION}

Relative humidity is the ratio, usually expressed in $\%$, of the partial pressure of water vapour to the saturation (equilibrium) vapour pressure of water at a given temperature.

Relative humidity depends on the temperature and pressure of the system of interest. As the air's temperature increases, it can hold more water molecules, decreasing its relative humidity. When temperatures drop, relative humidity increases. This is because colder air does not require as much moisture to become saturated as warmer air. $100 \%$ relative humidity of the air occurs when the air temperature is the same as the dew point value.

Table 1 shows the relationship between temperature and relative humidity. The slope and correlation between these two variables are shown in Figure 1. In this figure, it shows the correlation coefficient close to -1.0 .

Correlation coefficient is used to measure the strength of the relationship between two variables. The range of values for correlation coefficient is -1.0 to 1.0 . In other words, the values cannot exceed 1.0 nor be less than -1.0 .

Table 1: Relationship between temperature and relative humidity

\begin{tabular}{|c|c|}
\hline $\begin{array}{c}\text { Temperature } \\
/{ }^{\circ} \mathbf{C}\end{array}$ & $\begin{array}{c}\text { Relative Humidity } \\
\text { / \% } \mathbf{R H}\end{array}$ \\
\hline 16 & 64.3 \\
\hline 17 & 60.3 \\
\hline 18 & 56.6 \\
\hline 19 & 53.2 \\
\hline 20 & 50.0 \\
\hline 21 & 47.0 \\
\hline 22 & 44.2 \\
\hline 23 & 41.6 \\
\hline 24 & 39.2 \\
\hline
\end{tabular}

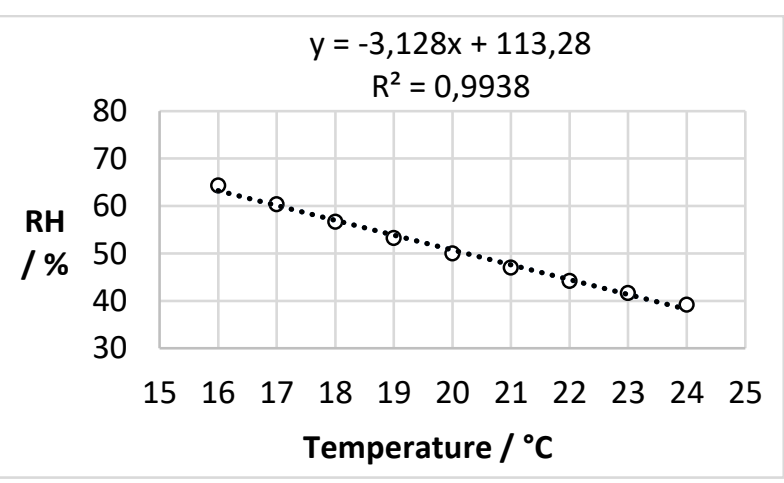

Figure 1: Correlation between temperature and relative humidity

\section{SUMMARY}

In mass comparison uncertainty evaluation, we need to consider all contributions that are of significant. Among them, one of the important uncertainty sources is air buoyancy correction. For air buoyancy correction, air density is the important parameter. Air density depends on the environmental conditions such as temperature, barometric pressure and humidity. The uncertainty of air density $u\left(\rho_{\mathrm{a}}\right)$ is calculated from the standard uncertainty of air pressure $u(p)$, temperature $u(t)$, and relative humidity $u(r h)$, together with their 
sensitivity coefficients, the partial derivatives of $\frac{\partial \rho_{\mathrm{a}}}{\partial p}, \frac{\partial \rho_{\mathrm{a}}}{\partial t}$, and $\frac{\partial \rho_{\mathrm{a}}}{\partial h r}$. However, when we use the ordinary partial differentiation, the derived value of $\frac{\partial \rho_{\mathrm{a}}}{\partial t}$ is not same as the value given in OIML R111. So, we need to consider the correlation between temperature and humidity when we perform partial differentiation of temperature against the air density.

We use August-Roche-Magnus approximation equation to determine the correlation between temperature and relative humidity. Finally, we can obtain the same value for $\frac{\partial \rho_{\mathrm{a}}}{\partial t}$ as given by OIML R111.

\section{ACKNOWLEDGEMENT}

The authors would like to thank PTB (Physikalisch-Technische Bundesanstalt) and its international cooperation project "Strengthening the
Quality Infrastructure in Myanmar", which supports and enables us to make this publication possible.

\section{REFERENCES}

[1] OIML R111 - Weights of classes $E_{1}, E_{2}, F_{1}, F_{2}, M_{1}$, $\mathrm{M}_{2}, \mathrm{M}_{3}$ Metrological and Technical Requirement, 2004.

[2] A. Picard, R. S. Davis, M. Gläser, K. Fujii, "Revised formula for the density of moist air (CIPM2007)", Metrologia, vol. 45, 2008, pp. 149155. DOI:

http://dx.doi.org/10.1088/0026-1394/45/2/004

[3] Guide to the Expression of Uncertainty in Measurement, ISO, 1995.

[4] Thomas K. Thiis, Ingunn Burud, Andreas Flø, Dimitrios Kraniotis, Stergiani Charisi, Petter Stefansson, Monitoring and Simulation of Diurnal Surface Conditions of a Wooden Façade, Procedia Environmental Sciences 38, 217, pp. 331-339. DOI: https://doi.org/10.1016/j.proenv.2017.03.088 